\title{
Del color de la arquitectura al color de la ciudad
}

Víctor Fernández Salinas, Dpto. de Geografía Humana, Universidad de Sevilla

\author{
Cualquier amenaza al \\ color de los edificios, \\ entre otros aspectos \\ que conforman su \\ carácter, \\ comprometería la \\ autenticidad de una \\ ciudad o área histórica
}

Mentar el color desde el patrimonio ha sido siempre para calificar el color de la arquitectura. Cartas de color, búsqueda de tonos originales u otros aspectos parecidos iban siempre relacionados con el carácter cromático que envolvía los edificios (a veces también respecto a sus interiores, aunque con una importancia muy inferior). Sin embargo, el debate de los colores no ha contado entre los más importantes del patrimonio. Entre las razones que explican esto está el hecho de que la pintura de un inmueble siempre se ha considerado un aspecto reversible y fácilmente restituible; por otro lado, también ha influido la mera inseguridad o la falta de investigaciones que permitiesen conocer con precisión los colores de los edificios en el pasado. A los estudiantes de arte griego siempre se les ha querido sorprender señalando cómo ese elegante, sobrio y suntuoso color del mármol que hoy tanto valoramos en la percepción contemporánea de los restos arqueológicos de la antigüedad estaba en las antípodas de la imagen que esos edificios tenían en la época clásica completamente pintados de colores llamativos y contrastados.

El color es percepción, pero también es autenticidad. La Carta para la Conservación de las Poblaciones y Áreas Históricas (Carta de Toledo-Washington de 1987) señala en su artículo segundo que cualquier amenaza al color de los edificios, entre otros aspectos que conforman su carácter (estructura, volumen, estilo, escala, materiales y decoración) comprometería la autenticidad de una ciudad o área histórica. Pero a estas alturas del siglo XXI, cuando la citada carta está siendo objeto de revisión, ¿se puede seguir identificando color de la arquitectura con el color o colores de la ciudad? Obviamente no. La ciudad histórica es por supuesto sus edificios, pero se compone también de elementos que poseen su color, o mejor, sus colores. La ciudad incluye elementos naturales que no sólo aportan gran variedad cromática, sino que además poseen una gran capacidad para cambiar durante las diferentes épocas del año o, simplemente, durante las horas del día. El agua o la vegetación aportan no sólo color, sino también movimiento, y en esta combinación cambiante, que ofrece infinitos matices, la imagen de la ciudad se multiplica y explica cómo a veces creemos estar ante dos ciudades distintas tras visitarlas una vez en diciembre y otra vez en mayo. La Carta de los Jardines Históricos (Carta de Florencia de 1981), ya un tanto caduca como la hoja de 


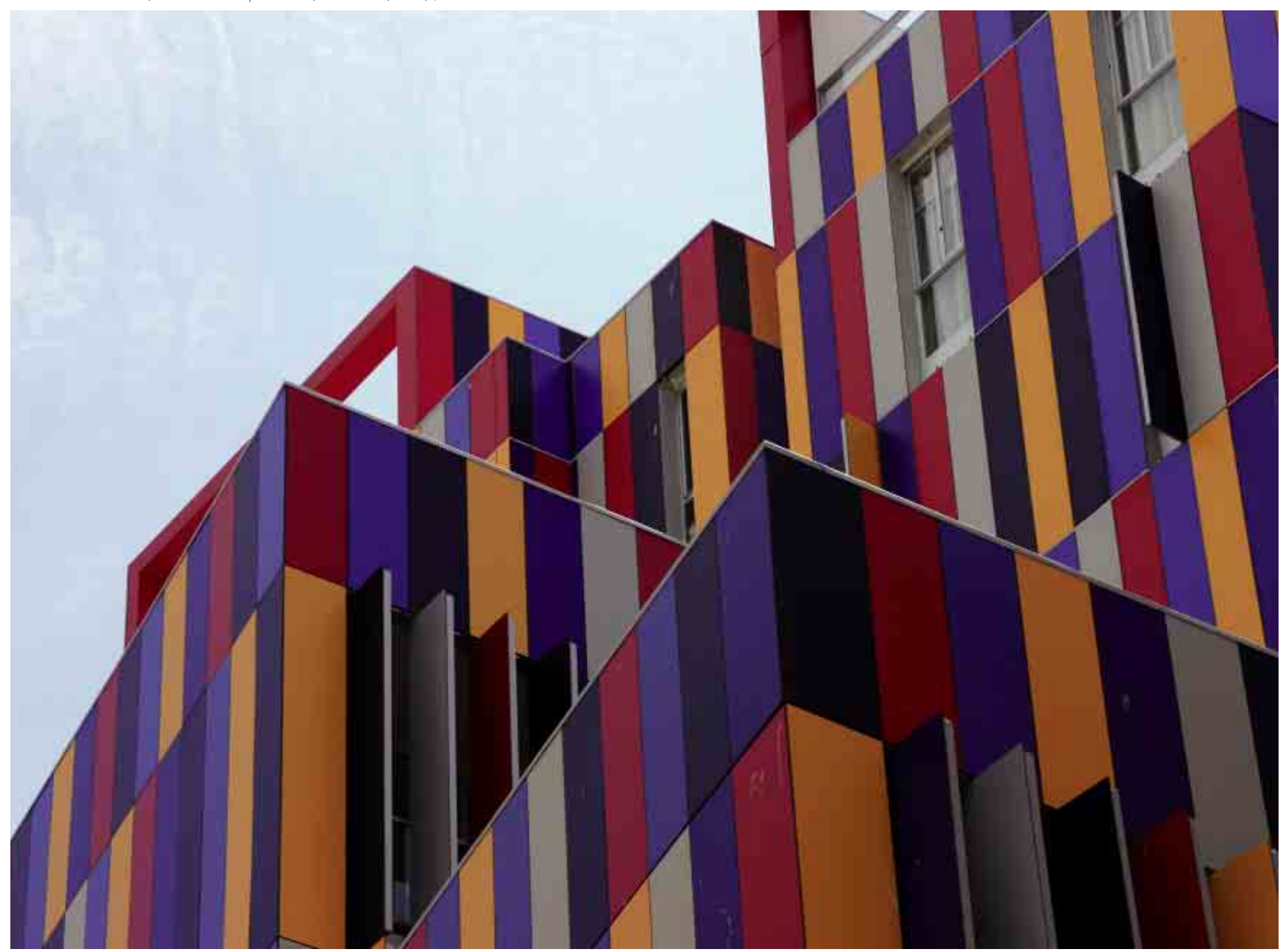




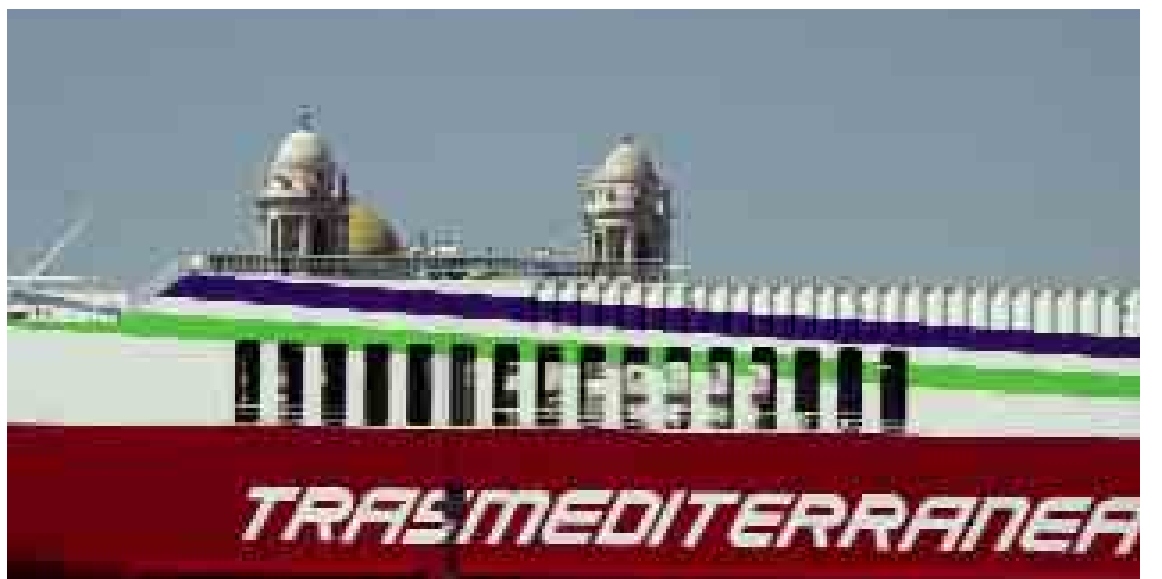

$\boldsymbol{\Theta}$ Puerto de Cádiz (2005) /

Foto: Víctor Fernández Salinas

( Plaza de Enrique García-Herrera, centro histórico de Málaga (2004) / Foto: Víctor Fernández SALINAS

(-) Torre del Oro en rehabilitación (2005)

FOTO: VíctOR FERNÁNDEZ SALINAS

- El color de los pavimentos, plaza de San Juan de Dios, Cádiz (2007) / Foto: Víctor FeRnández SALINAS
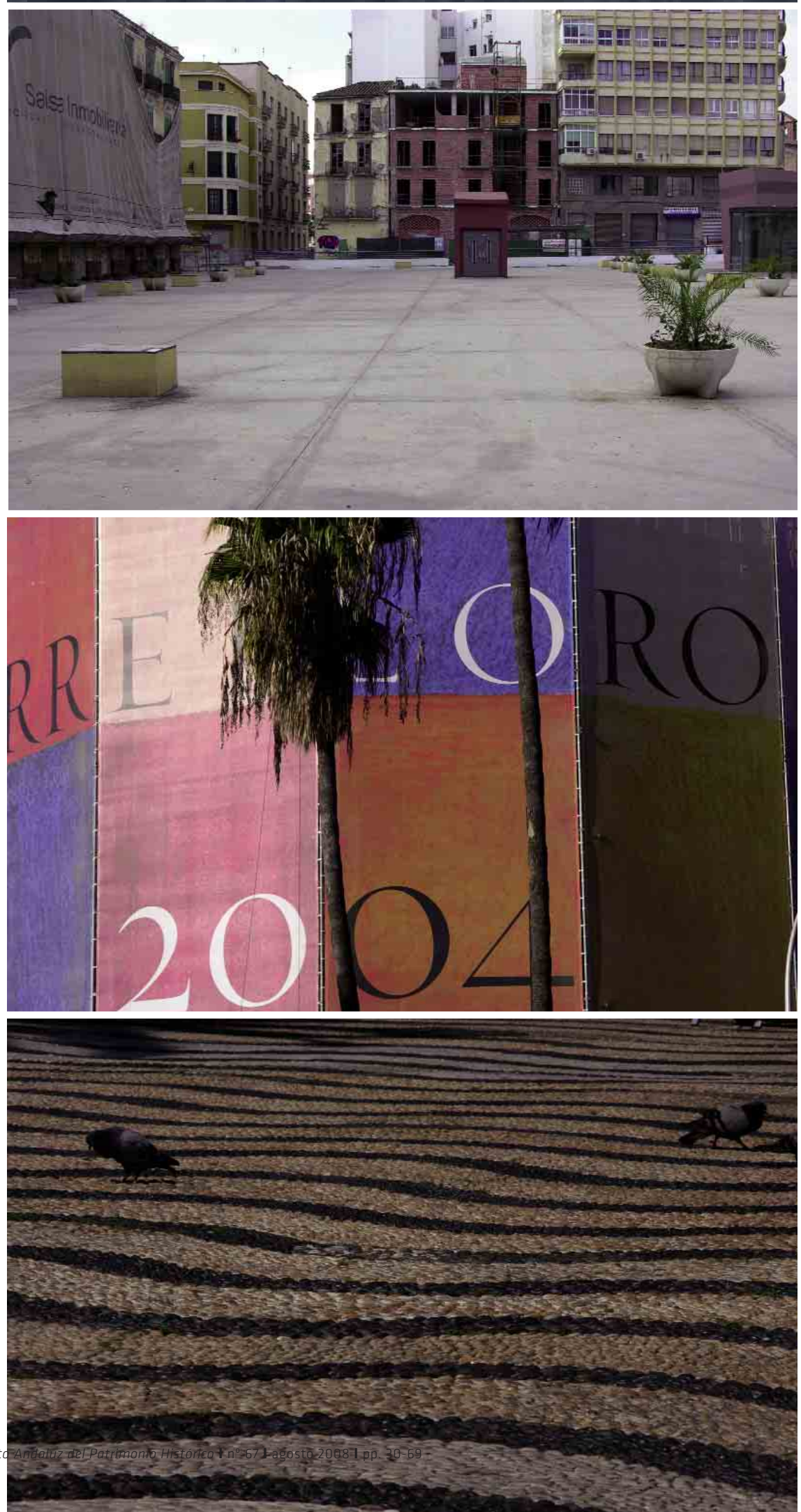
algunos de los árboles que pretende proteger, recoge estos aspectos y les otorga rango patrimonial, aunque sólo se interesa por aquellos lugares que son jardines o sitios históricos. Realmente este carácter mutante gracias al color lo posee toda ciudad y toda zona urbana, se correspondan con los lugares que interesan a la carta o no.

El color es un recurso para componer, recomponer y volver a cualificar cualquier entorno urbano y especialmente lo es en espacios históricos degradados, marginales o con problemas para generar identidad y sociabilidad. Estas consideraciones llevan a que en la actualidad se mantengan equipos de investigación ocupados en la determinación de los colores de la arquitectura y otros elementos como fuente para conocer mejor el patrimonio y tener más elementos de juicio a la hora de tomar decisiones sobre qué color/colores deben ser fomentados en una zona o población determinada, en tanto que otros se plantean cómo los elementos urbanos, antiguos y nuevos, funcionan de forma diferente en la imagen urbana en razón del color con el que se les revista.

Este resurgimiento del color como recurso urbano se combina paradójicamente y al mismo tiempo con tratamientos de los espacios públicos que son monocromos, duros, extensivos, aburridos y, lo que es más grave, clónicos y estandarizados en miles de ciudades del planeta. Mientras que los edificios y todo lo que está sobre rasante ha descubierto el color como elemento que aporta carácter, dignidad y distinción, los suelos de la ciudad han sustituido en buena medida el gris oscuro casi negro del asfalto de los años sesenta y setenta por el granito gris más claro de principios del milenio o simplemente por hormigón como sucede incluso en algunos centros históricos (véase imagen p. 34 de la plaza de Enrique García-Herrera).

Existen aún espacios patrimoniales en los que el color continúa siendo una especie de tabú, sobre todo en los yacimientos arqueo- lógicos. No se aconsejará desde estas líneas que una marea de color mejore la imagen de estos espacios sagrados del pasado; pero, desde luego, tampoco se negará que la incorporación de elementos de color puede servir para una interpretación más completa y sencilla de tales espacios, con la ventaja de que estos elementos son fácilmente reversibles. Al contrario, el patrimonio inmaterial está normalmente bien asociado a una rica gama de colores. La fiesta, el rito, y todo aquello que pretende revestirse de un carácter excepcional saben bien cómo aprovechar los colores para transmitir esta idea de tiempo cargado de significados distintos de los del corriente devenir. La ciudad se traviste en la fiesta, en el luto, en la celebración, y el color proporciona las claves que todo ciudadano entiende y comparte.

El color de la ciudad, en toda su dinámica cambiante, es pues, más que otra cosa, identidad. El mundo del patrimonio cultural, y especialmente el de la gestión de las ciudades, no ha recalado mucho en este aspecto, o al menos mucho más allá de conocer la paleta de colores tradicionales de una población (aunque a menudo esa paleta tradicional sólo obedece a un período histórico en el que tales colores se conocían mejor o que coincidía con una etapa especial de la ciudad). El futuro depara más y nuevos debates, y éstos no se ceñirán a los límites de los conjuntos históricos, sino que atañerán al conjunto de la ciudad y a la forma en que ésta se inserta en el territorio. La gran obra pública así lo está entendiendo y este número del PH Boletín del IAPH lo confirma. Se apunta hacia una cromourbanística que será al urbanismo lo que la cromoterapia a la medicina. Está aún sin desarrollar, sí, pero ya hay experiencias interesantes y muchos compartimos que lo mejor del color está por llegar.

\section{El color es un recurso} para componer, recomponer y volver a cualificar cualquier entorno urbano, especialmente espacios históricos degradados, marginales o con problemas de identidad 


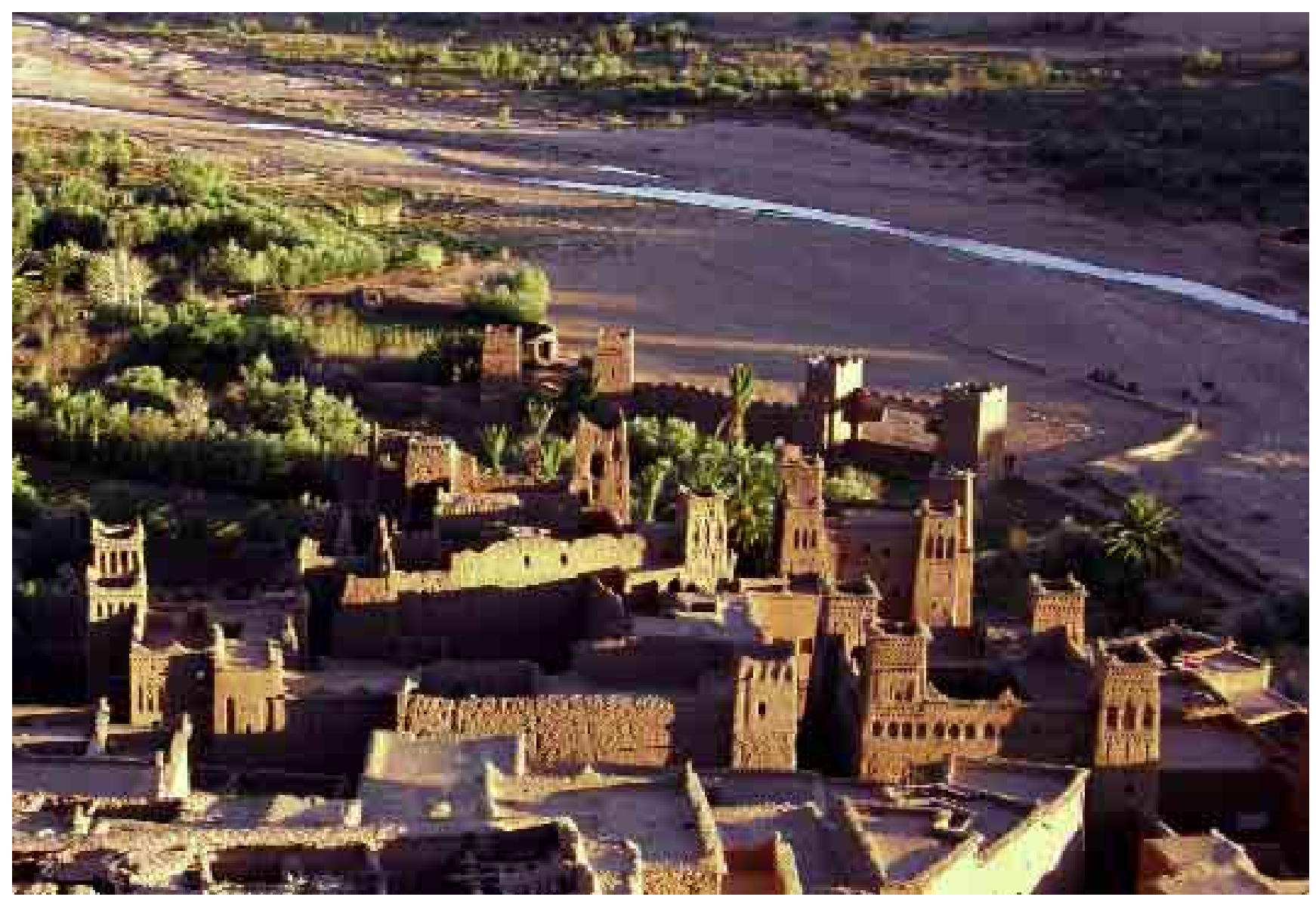

Ciudad del alto Atlas marroquí, próxima a Ouarzazate, cuya arquitectura de adobe y tapial, sin acabados que la maquillen, es una prolongación cromática de la tierra circundante / Foto: FLORENTINO POZO

Hay una relación

estrecha entre desarrollo

cultural-tecnológico y la

tipología, variedad y

mutabilidad del empleo

del color 